\title{
Segurança nos serviços emergenciais em redes elétricas: os fatores ambientais.
}

\author{
Luiz Antonio Melo, M.Sc. \\ Engenheiro da Light, Professor da UNIABEU - RJ \\ E-mail: luizantonio.melo@globo.com \\ Gilson Brito Alves Lima, D.Sc. \\ Engenheiro de Segurança do Trabalho, Professor Adjunto - UFF / CTC / TEP \\ E-mail: gilson@latec.uff.br \\ Nelson Damieri Gomes, M.Sc. \\ Engenheiro da Siemens, Professor da UNIABEU - RJ \\ E-mail:prof4277@abeunet.com.br
}

RuI Soares, M.Sc.

Professor da UNIABEU - RJ

E-mail: rsoares@aol.com

\begin{abstract}
Resumo
O artigo apresenta um estudo, desenvolvido em uma empresa concessionária de energia elétrica, com o objetivo de identificar os principais fatores relativos aos ambientes de trabalho, que contribuem para a ocorrência de acidentes nos serviços emergenciais em redes aéreas de distribuição de energia elétrica. 0 estudo consiste na análise das instruções normativas e dos modos operatórios originais, desenvolvidos pelos próprios trabalhadores, face aos imprevistos e incertezas decorrentes da natureza emergencial dos serviços. Também são identificados os tipos de acidentes mais comuns relacionados à atividade e sua correlação com os fatores ambientais, constituindo -se num importante elemento para o desenvolvimento de um sistema de prevenção de acidentes para todas as empresas que atuam em serviços emergenciais nas redes aéreas de distribuição de energia elétrica.
\end{abstract}

Palavras-chave

Fatores ambientais, segurança, energia elétrica.

\section{Safety in the emergency services in the electric lines: the environmental factors.}

\begin{abstract}
This paper presents a study, developed in a concessionary company of electric energy, looking for to identify the environmental factors that contribute to the occurrence of accidents in the emergency services in the overhead distribution lines of electric energy. The study, analyzes the normative instructions for the work and the original operative manners, developed by the own workers, face to the unexpected ones and current uncertainties of the nature emergencial of the services. Was also identified the types of more common accidents related to the activity and it's correlation with the environmental factors, if constituting in an important element for the development of a prevention system of accidents for all the companies that act in emergency services in the overhead distribution lines of electric energy.
\end{abstract}

Key words

Environmental factors, safety, electric energy. 


\section{INTRODUĈ̣̃O}

As informações sobre a expectativa de vida no Brasil revelam que os brasileiros estão vivendo mais, o que induz a acreditar que a saúde do povo está melhor e que a morte entre os mais jovens não ocorre de forma natural, mas sim pela influência de outros fatores. Dentre estes fatores encontram-se os acidentes do trabalho como uma causa "absurda" que engrossa esta estatística.

Segundo dados do Ministério da Previdência, no ano de 1999 ocorreram 3.605 mortes provenientes de um total de 393.628 acidentes de trabalho. O número real de acidentes de trabalho ocorridos no Brasil deve ser, no mínimo, o dobro dos dados registrados pelas estatísticas oficiais. É que nas contas da Previdência não aparecem registros referentes aos trabalhadores do mercado informal, servidores públicos e nem mesmo os contribuintes individuais do INSS, como autônomos e outros (Jornal do Brasil, 25/03/01).

Em determinadas situações, quando ocorrem acidentes de grandes proporções as atenções se voltam para a questão da prevenção de acidentes, talvez mais pela repercussão e o valor do dano do que, propriamente, pelos operários acidentados.

Considera-se, entretanto, que não existe dano maior do que a perda de vidas humanas, fato que ocorre diariamente nos diferentes tipos de atividades profissionais.

Em algumas atividades, ditas perigosas, como os serviços em redes de energia elétrica, ainda ocorrem graves acidentes, mesmo contando com padrões preestabelecidos de segurança.

A rede de distribuição aérea de energia elétrica normalmente é constituída por condutores sobre estruturas de ferro ou madeira, apoiadas nos postes de concreto ou madeira. Essa rede se estende por toda região urbana e rural onde houver consumidores instalados.

$\mathrm{Na}$ realidade, condutores, postes e estruturas fazem parte da paisagem e da vida cotidiana das pessoas. Elas aprendem a conviver com as utilidades e os perigos das redes aéreas de distribuição. Apesar da padronização das estruturas, as características de cada ponto são as mais diversificadas, variando por bairro, rua e poste, devido à influência do meio ambiente.

Esses fatos tornam os serviços realizados na rede bastante complexos, haja vista as condições diferenciadas de cada local bem como a conseqüente dificuldade em orientar, programar e planejar os serviços.

A situação se agrava na realização dos serviços não programados (serviços emergenciais), cujo principal objetivo é o rápido restabelecimento do fornecimento de energia, quando interrompido. Na maioria das vezes, os serviços de caráter emergencial são realizados a qualquer hora e em qualquer local, geralmente, sob pressão dos clientes, da opinião pública e da própria empresa.

O controle de riscos é também bastante complexo em virtude da multiplicidade de combinações de acontecimentos e suas conseqüências.

Mesmo as concessionárias possuindo e utilizando manuais de procedimentos técnicos e de segurança, referentes às atividades desenvolvidas, ainda ocorrem vários acidentes de trabalho e incidentes (geralmente não relatados pelas equipes). Esses manuais, normalmente sofrem atualizações em função do resultado das investigações e análise dos acidentes ocorridos.
Machado; Porto \& Freitas (2000) alertam que várias concepções das análises de acidentes tendem a culpar os trabalhadores (as próprias vítimas), limitando o aprendizado das organizações com suas falhas. Principalmente quando se considera que esse tipo de análise limitado é empregado freqüentemente no Brasil, encontrando-se ainda presente em diversas concepções oficiais sobre acidentes de trabalho, como nas normas da Associação Brasileira de Normas Técnicas (ABNT) e na Comunicação de Acidente de Trabalho (CAT) do Instituto Nacional do Seguro Social (INSS), em que há um campo específico para o preenchimento do objeto causador.

Nos serviços emergenciais, além da exposição à energia elétrica, existem os perigos relacionados ao meio ambiente. Esses perigos são de difícil previsão e prevenção, podendo se constituir em causas indiretas de vários acidentes.

A prevenção, em relação aos riscos provenientes dos procedimentos técnicos, pode ser melhorada ao longo do tempo, pois os riscos, em sua maioria, são conhecidos e podem ser facilmente mapeados e controlados. As interferências e consequiências dos fatores relacionados ao meio ambiente, entretanto, não são bem conhecidas e nem divulgadas, principalmente devido ao aspecto localizado e imediatista das análises de acidentes, conforme descrito anteriormente.

Este artigo, portanto, tem como objetivo identificar os principais fatores ambientais característicos dos serviços emergenciais em redes aéreas de distribuição de energia elétrica, que contribuem para a ocorrência dos acidentes de trabalho, visando a melhoria dos métodos de prevenção existentes.

Além dos fatores ambientais outros fatores influenciam 
a ocorrência de acidentes do trabalho nos serviços emergenciais em redes aéreas de distribuição de energia elétrica, como os fatores pessoais, sociais, gerenciais, organizacionais, etc. Optamos, entretanto, pelo estudo dos fatores ambientais devido a sua relação direta com a imprevisibilidade dos serviços emergenciais. se a seguir, resumidamente, algumas características componentes dos Sistemas de Distribuição de Energia Elétrica. Não se pretende aprofundar nos aspectos ligados à Engenharia Elétrica no campo dos Sistemas de Potência, mas apenas inserir o leitor no ambiente onde são realizadas as atividades operacionais e onde ocorrem a maioria dos acidentes.

A energia elétrica gerada nas usinas (Hidrelétrica, Térmica ou Nuclear) para chegar ao consumidor final passa por processos de transformação que modificam os níveis de tensão com o objetivo de diminuir as perdas inerentes ao processo de transmissão e a ade-

As principais questões a serem apuradas referem-se ao nível de insegurança dos serviços emergenciais, à influência dos fatores ambientais na ocorrência de acidentes e à importância do fator pessoal na prevenção de acidentes nos serviços em redes aéreas de distribuição de energia elétrica.

\section{CARACTERIZAC̣ÃO DA EMPRESA ESTUDADA}

O estudo desenvolveu-se na Light, empresa concessionária de energia elétrica do Estado do Rio de Janeiro, responsável pela distribuição de energia elétrica no Município do Rio de Janeiro e Municípios da Baixada Fluminense e Vale do Paraíba.

A Light divide sua área de concessão em quatro Superintendências Regionais: Litorânea, Leste, Oeste e Interior. O estudo se desenvolveu na Superintendência Regional Oeste, que é responsável pelos serviços na Zona Oeste no Município do Rio de Janeiro e também nos Municípios de Nova Iguaçu e Belford Roxo. Essas regiões possuem características bem diversas, reunindo áreas oceânicas, urbanas e rurais, proporcionando, assim, considerável representatividade no que concerne aos ambientes de trabalho. As principais características da Regional Oeste são mostradas no quadro 1 .

Quase todos os serviços operacionais são terceirizados, com exceção dos serviços emergenciais, nos quais a empresa mantém em torno de $50 \%$ de mão-de-obra própria, visando as manobras nas redes de Alta Tensão (AT). No total, a quantidade de mão-de-obra própria representa aproximadamente apenas $30 \%$ do efetivo operacional, ficando a maior parte dos serviços por conta das empresas contratadas.

\section{O SISTEMA DE DISTRIBUIC̣ÃO DE ENERGIA ELÉTRICA}

Para um melhor entendimento dos aspectos da segurança do trabalho nos serviços em redes de distribuição, apresenta- quação aos limites requeridos pelos consumidores. (MORAES, 2001, p.16)

Para melhor compreensão do processo de distribuição de energia elétrica apresentamos o esquema, representado na Figura 1, que exemplifica o processo desde a geração da energia até à instalação dos consumidores.

A energia elétrica, produzida na usina geradora, é transmitida às subestações abaixadoras, através de linhas condutoras chamadas "Linhas de Transmissão", em Alta Tensão (AT- tensões acima de $69 \mathrm{kV}$ ). As subestações abaixadoras, localizadas em pontos estratégicos, próximo aos grandes centros de consumo, transformam a energia de Alta para Média Tensão (MT - normalmente tensões de $7 \mathrm{kV}$ a $69 \mathrm{kV})$. A energia é então conduzida aos diversos bairros através das "Linhas de Distribuição Primárias" (em

Quadro 1: Características da Light - Regional Oeste.

\section{CARACTERÍSTICAS DA REGIONAL OESTE}

\begin{tabular}{|l|c|}
\hline Mão-de-obra Própria & Quantidade \\
\hline Gerentes & 6 \\
\hline Administrativos & 43 \\
\hline Profissionais (nível superior) & 26 \\
\hline Técnicos (nível médio) & 130 \\
\hline Operacionais & 205 \\
\hline Características Técnicas & Quantidade \\
\hline Área de atendimento (km²) & 1.312 \\
\hline Circuitos de AT & 326 \\
\hline Extensão dos Circuitos de AT (km) & 3.898 \\
\hline Transformadores de distribuição & 17.337 \\
\hline Subestações & 39 \\
\hline Clientes & 1.034 .912 \\
\hline Atendimentos de emergência/ mês & 7.000 \\
\hline
\end{tabular}


MT) até os chamados "Transformadores de Distribuição", instalados nos postes e câmaras subterrâneas, ou abrigados em dependências prediais (subestações consumidoras) de consumidores de médio porte. Dos Transformadores de Distribuição para os consumidores industriais e comerciais de pequeno porte e grupos residenciais, a energia é conduzida pelas "Linhas de Distribuição Secundárias", em Baixa Tensão (BT - normalmente tensões de $127 \mathrm{~V}$ a 440V) (ELETROBRÁS, 1982).

A rede de distribuição de energia elétrica a que nos referimos trata-se, portanto, de todos os componentes do sistema elétrico situados desde a saída da subestação até a entrada das instalações dos consumidores, em Média e Baixa Tensão. O termo "Média Tensão" é utilizado normalmente pelas concessionárias de energia elétrica, porém, de uma forma geral, utilizam-se apenas os termos "Baixa Tensão" e "Alta Tensão", com esta última englobando também a MT.

As redes de distribuição podem ser aéreas ou subterrâneas. No Brasil predomina a rede aérea, ficando a rede subterrânea restrita a alguns grandes centros com forte concentração de carga.
O objetivo institucional de uma empresa distribuidora de energia elétrica é fornecer a energia ao cliente, dentro dos padrões de qualidade estabelecidos pela Agência Nacional de Energia Elétrica (ANEEL), órgão regulador governamental. A qualidade, nesse caso, é representada pela continuidade do fornecimento e os níveis de tensão entregues aos clientes.

Para descrever as atividades operacionais de uma empresa distribuidora de energia elétrica, elaboramos um resumo, apresentado no Quadro 2, contendo as principais atividades operacionais.

\section{OS REPAROS EMERGENCIAIS}

Dentre as atividades operacionais desenvolvidas pelas concessionárias de energia elétrica, todas aquelas que envolvem interrupção e restabelecimento do fornecimento têm, sem dúvida, importância bastante considerável não só pelos aspectos institucionais e qualitativos representados pela perda da continuidade do sistema elétrico como também pelos aspectos financeiros decorrentes da perda de receita.

\section{Figura 1: Processo de Distribuição de Energia Elétrica.}

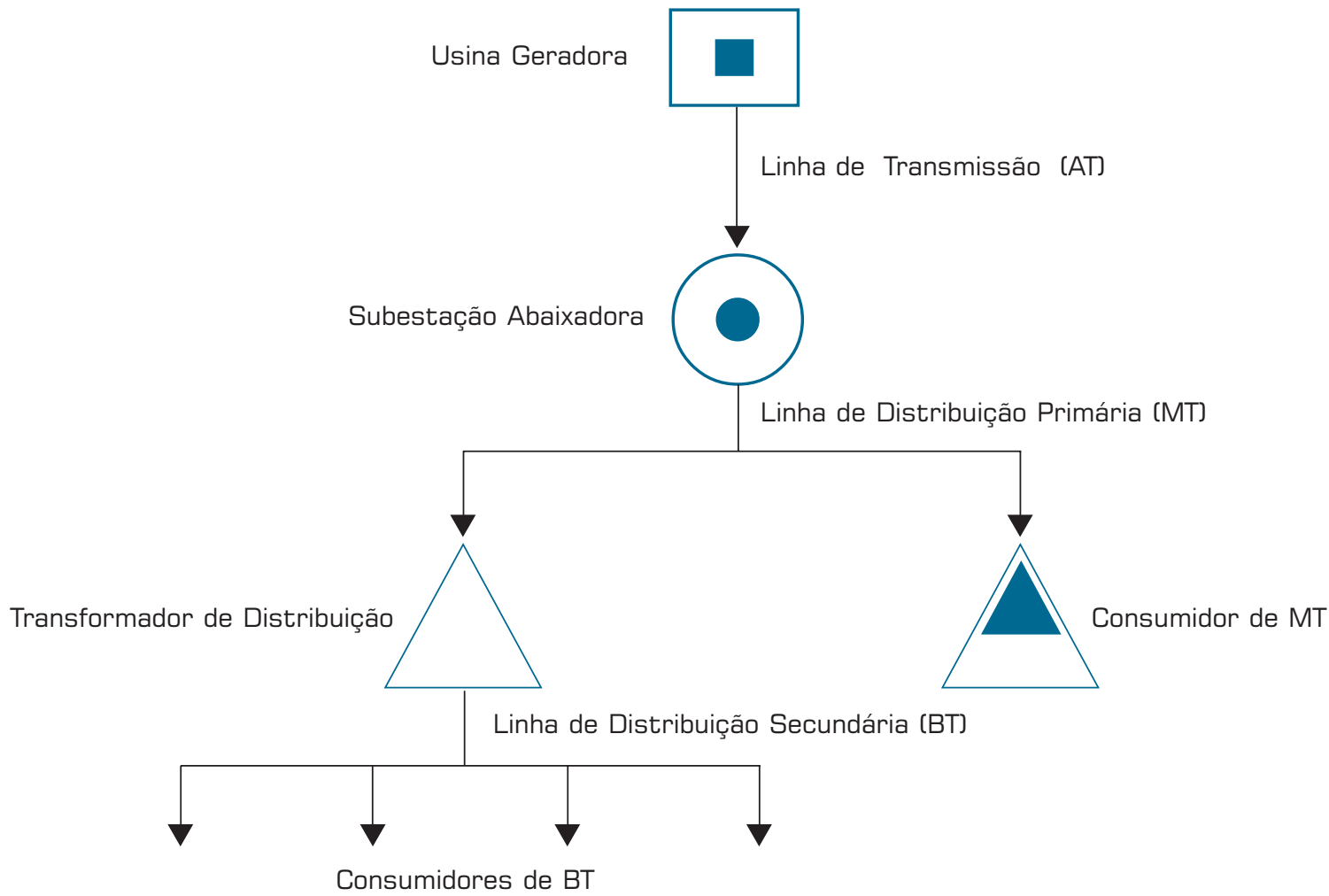

Fonte: Adaptado de Creder (1986). 
A dependência da energia elétrica é tão grande na civilização moderna que a sua falta pode acarretar transtornos imensuráveis a toda sociedade, desde grandes empresas até a mais humilde residência. Na verdade, o desejo das concessionárias seria que nunca houvesse interrupção de energia, fato que não depende apenas da empresa, já que o sistema de distribuição está exposto às intempéries do meio ambiente (SENIA, 2001).

Se por ventura a normalização depender de um reparo mais trabalhoso são acionadas as equipes de manutenção, equipadas com ferramentas e equipamentos pesados. Os serviços emergenciais são realizados a qualquer momento, em qualquer local e sob quaisquer circunstâncias.

O quadro 3 mostra os reparos mais freqüentes nas redes aéreas de distribuição, segundo os relatórios das turmas de emergência da Light.

Percebemos que as equipes de emergência são responsáveis pela grande maioria dos serviços emergenciais em redes de distribuição, onde a principal característica dos riscos fica por conta da imprevisibilidade dos reparos e da rapidez exigida, não permitindo, na

Diferente da maioria dos negócios, para os clientes das concessionárias o fato de receber energia ininterruptamente e em níveis que atendam suas necessidades é uma obrigação da empresa, não importando os limites estabelecidos pelo órgão regulador governamental.

Dessa maneira, as empresas devem estar preparadas para restabelecer o fornecimento ao cliente o mais rápido possível. Como as falhas podem ocorrer a qualquer momento, as empresas mantêm equipes específicas para o atendimento das reclamações de falta de energia, que pode envolver apenas uma residência, algumas ruas ou mesmo bairros inteiros (MUSSER, 2001).

Essas equipes, chamadas "turmas de emergência", são geralmente compostas por dois eletricistas treinados para realizar pequenos reparos visando o restabelecimento imediato do fornecimento, o que representa a maioria dos casos. maioria dos casos, um planejamento adequado para as tarefas. O grau de complexidade dos reparos dependerá da situação em cada local específico onde a tarefa será realizada.

\section{O AMBIENTE DE TRABALHO}

A NBR 14280, seção 2.8.3, refere-se à Condição Ambiente de Insegurança (Condição Ambiente) como sendo o meio que causou o acidente ou contribuiu para sua ocorrência. E acrescenta que o adjetivo "ambiente" inclui tudo que se refere ao meio, desde a atmosfera do local de trabalho até as instalações, equipamentos, substâncias utilizadas e métodos de trabalho empregados.

Diariamente, o ambiente, as ferramentas, as máquinas e as posturas assumidas, dentre outras variáveis presentes no ambiente de trabalho, nos colocam à mercê de danos à

Quadro 2: Principais atividades operacionais de uma empresa de distribuição de energia elétrica.

\begin{tabular}{|c|c|c|}
\hline ATIVIDADE & DESCRIÇÃO & OBJETIVO \\
\hline Construção de redes & $\begin{array}{l}\text { Projeta e executa a instalação e reforma das } \\
\text { redes de distribuição. }\end{array}$ & $\begin{array}{l}\text { Expandir e/ou melhorar o sistema } \\
\text { distribuidor. }\end{array}$ \\
\hline Manutenção & $\begin{array}{l}\text { Efetua intervenções visando eliminar defeitos } \\
\text { que possam interromper o fornecimento. }\end{array}$ & $\begin{array}{l}\text { Manter a continuidade do } \\
\text { fornecimento. }\end{array}$ \\
\hline Emergência & $\begin{array}{l}\text { Efetua intervenções visando restabelecer o } \\
\text { fornecimento após a ocorrência de falha no } \\
\text { sistema. }\end{array}$ & $\begin{array}{l}\text { Restabelecer imediatamente o } \\
\text { fornecimento de energia ao cliente. }\end{array}$ \\
\hline Ligação & $\begin{array}{l}\text { Efetua a ligação das instalações dos clientes } \\
\text { ao sistema distribuidor. }\end{array}$ & Ligar novos clientes. \\
\hline Corte & $\begin{array}{l}\text { Desliga as instalações dos clientes por falta } \\
\text { de pagamento. }\end{array}$ & Garantir a receita. \\
\hline Religação & Religa as instalações dos clientes. & Garantir a receita. \\
\hline
\end{tabular}


nossa integridade e à nossa saúde, consistindo nos chamados riscos ambientais (LIMA, 2000).

Nos serviços em redes de distribuição de energia elétrica, o ambiente de trabalho é constituído pelas ruas. O trabalho ao ar livre, como alguns costumam chamar, faz com que, além dos riscos inerentes às atividades, o trabalhador se exponha a todas as outras variáveis que influenciam a vida normal de qualquer pessoa, inclusive por manifestações da natureza.
A NR 9 considera como riscos ambientais "os agentes físicos, químicos e biológicos existentes nos ambientes de trabalho que, em função de sua natureza, concentração ou intensidade e tempo de exposição, são capazes de causar danos à saúde do trabalhador"(BRASIL, 1997).

Os riscos químicos representam os elementos presentes no campo de atuação da toxicologia, que estuda os efeitos nocivos decorrentes das interações de substâncias quími-

Quadro 3: Reparos mais freqüentes nas Redes Aéreas de Distribuição.

\begin{tabular}{|c|c|c|c|c|}
\hline DEFEITO & SINTOMA DE FALHA & REPARO & ABRANGÊNCIA & TIPO DE EQUIPE \\
\hline $\begin{array}{l}\text { Defeito no ponto } \\
\text { de medição. }\end{array}$ & $\begin{array}{l}\text { Falta ou oscilação } \\
\text { de energia. }\end{array}$ & $\begin{array}{l}\text { Substituição do medidor, } \\
\text { subst. do fusível, reaperto. }\end{array}$ & Uma residência & Emergência. \\
\hline $\begin{array}{l}\text { Ramal de ligação } \\
\text { partido. }\end{array}$ & $\begin{array}{l}\text { Falta ou oscilação } \\
\text { de energia. }\end{array}$ & $\begin{array}{l}\text { Emenda ou substituição } \\
\text { do condutor. }\end{array}$ & $\begin{array}{l}\text { Uma ou mais } \\
\text { residências }\end{array}$ & Emergência \\
\hline $\begin{array}{l}\text { Defeito na conexão } \\
\text { do ramal de ligação. }\end{array}$ & $\begin{array}{l}\text { Falta ou oscilação } \\
\text { de energia. }\end{array}$ & Substituição do conector. & $\begin{array}{l}\text { Uma ou mais } \\
\text { residências }\end{array}$ & Emergência \\
\hline $\begin{array}{l}\text { Rede de Baixa } \\
\text { Tensão partida. }\end{array}$ & $\begin{array}{l}\text { Falta ou oscilação } \\
\text { de energia. }\end{array}$ & Emenda da rede. & Uma ou mais ruas & $\begin{array}{l}\text { Emergência } \\
\text { ou Manutenção }\end{array}$ \\
\hline $\begin{array}{l}\text { Defeito na conexão } \\
\text { da rede de Baixa } \\
\text { Tensão. }\end{array}$ & $\begin{array}{l}\text { Falta ou oscilação } \\
\text { de energia. }\end{array}$ & Substituição do conector. & Uma ou mais ruas & Emergência \\
\hline $\begin{array}{l}\text { Poste tombado ou } \\
\text { quebrado na rede de } \\
\text { Baixa Tensão. }\end{array}$ & Falta de energia. & $\begin{array}{l}\text { Reinstalação ou } \\
\text { substituição do poste. }\end{array}$ & Uma ou mais ruas & Manutenção \\
\hline $\begin{array}{l}\text { Defeito no } \\
\text { transformador de } \\
\text { distribuição. }\end{array}$ & $\begin{array}{l}\text { Falta ou oscilação } \\
\text { de energia. }\end{array}$ & $\begin{array}{l}\text { Substituição do } \\
\text { transformador. }\end{array}$ & Uma ou mais ruas & Manutenção \\
\hline $\begin{array}{l}\text { Queima do fusível do } \\
\text { transformador. }\end{array}$ & $\begin{array}{l}\text { Falta ou oscilação } \\
\text { de energia. }\end{array}$ & Substituição do fusível. & Uma ou mais ruas & Emergência \\
\hline $\begin{array}{l}\text { Defeito na conexão } \\
\text { da rede de Média } \\
\text { Tensão. }\end{array}$ & $\begin{array}{l}\text { Falta ou oscilação } \\
\text { de energia. }\end{array}$ & Substituição do conector. & Um ou mais bairros & Emergência \\
\hline $\begin{array}{l}\text { Defeito em } \\
\text { interruptores de } \\
\text { Média Tensão. }\end{array}$ & $\begin{array}{l}\text { Falta ou oscilação } \\
\text { de energia. }\end{array}$ & $\begin{array}{l}\text { Substituição do } \\
\text { interruptor. }\end{array}$ & Um ou mais bairros & Emergência \\
\hline $\begin{array}{l}\text { Defeito em } \\
\text { isoladores da rede } \\
\text { de Média Tensão. }\end{array}$ & Falta de energia. & Substituição do isolador. & Um ou mais bairros & Emergência \\
\hline $\begin{array}{l}\text { Galho de árvore ou } \\
\text { outro objeto sobre a } \\
\text { rede. }\end{array}$ & Falta de energia. & $\begin{array}{l}\text { Corte ou retirada do } \\
\text { galho ou de objetos. }\end{array}$ & Um ou mais bairros & $\begin{array}{l}\text { Emergência ou } \\
\text { Manutenção }\end{array}$ \\
\hline $\begin{array}{l}\text { Poste tombado ou } \\
\text { quebrado na Média } \\
\text { Tensão. }\end{array}$ & Falta de energia. & $\begin{array}{l}\text { Reinstalação ou } \\
\text { substituição do poste. }\end{array}$ & Um ou mais bairros & Manutenção \\
\hline
\end{tabular}

Fonte: Relatórios de Atendimento de Emergência. Light - Regional Oeste 
cas com o organismo. Entre essas formas, destacam-se as névoas, neblinas, fumos, poeiras, gases e vapores.

Os riscos biológicos relacionam-se à capacidade de organismos vivos - bactérias, fungos, helmintos, protozoários e vírus, entre outros chamados patogênicos - causarem doenças ao organismo humano.

Riscos físicos são aqueles que compreendem danos de variáveis como ruído, vibração, temperaturas extremas (altas e baixas), pressões anormais, radiações ionizantes e não ionizantes.

Barbosa Filho (2001) acrescenta aos citados mais dois grupos de riscos, que são os riscos de acidentes e os riscos ergonômicos.

Os riscos de acidentes são decorrentes da presença material de oportunidades de dano resultantes do atrito entre peças, partes móveis, arestas cortantes, sistemas motores desprotegidos, etc. Outros autores também utilizam a classificação de riscos de acidentes, como a presença de piso irregular, o trânsito de meios de deslocamento de cargas, fiação exposta, etc.

Os riscos ergonômicos podem assumir uma variada gama de particularidades. Vão desde uma inadequação antropométrica, situações bastante comuns em nossas empresas, até mesmo a discussões acerca da prescrição das tarefas e das informações fornecidas para seu cumprimento. Da interpretação dos sinais e do reconhecimento dos comandos e das ações requeridas em sua execução; do controle de mecanismos; da análise da jornada, passando pelas posturas viciosas e exigências individuais; a condição de conforto oferecida pela vestimenta e calçados; pela rotina de atividades, habilidades e preferências pessoais do trabalhador, respeitando-se as mais distintas diferenças individuais, resultando numa adaptação deste ao seu trabalho e vice-versa.

Melo (2002) observa que para efeito de análise das atividades em redes de distribuição é necessário acrescentar aos riscos citados, anteriormente, a influência social ou os riscos sociais, que se referem às atitudes da comunidade $\mathrm{e}$ outros riscos próprios da vida urbana, inclusive a violência, um dos maiores problemas urbanos das grandes cidades do País atualmente.

Os serviços das empresas de distribuição de energia elétrica interferem na rotina das pessoas, não apenas, pela interrupção do fornecimento, mas também pelas mudanças e transtornos físicos causados pela execução das atividades. Essas interferências podem gerar atitudes negativas da comunidade com reflexo nos aspectos da segurança dos trabalhadores.

Os trabalhadores em serviços nas redes de distribuição estão praticamente expostos a quase todos os tipos de riscos porquanto o local de trabalho inclui toda a área geográfica de atuação da concessionária. A mesma equipe pode reali- zar serviços em uma área rural, com insetos, cobras e outros animais, como pode trabalhar na área urbana com trânsito intenso e grande pressão social. Pode efetuar o trabalho sob sol ou chuva intensa; ventania; brejos; esgoto; próximo ou dentro de residências, comércio e indústrias das mais variadas atividades.

Melo (2002) aponta três fatores permanentes no trabalho das equipes nos serviços em redes aéreas de distribuição como condicionantes para o nível de risco da atividade: o trabalho em altura, o trabalho com eletricidade e o trabalho nas ruas.

Para os dois primeiros, existem condições de controle que se não eliminam os riscos, pelo menos diminuem sua intensidade. Para o trabalho nas ruas, praticamente não existe nenhuma forma de controle, ficando por conta de recomendações de caráter geral.

Mesmo existindo nas empresas normas e padrões de controle para o trabalho em altura e o trabalho com eletricidade, a característica física de cada local não permite, algumas vezes, o cumprimento das regras estabelecidas. Tal fato faz com que os eletricistas improvisem procedimentos por conta própria. O próprio treinamento para as atividades envolve as situações-padrões estabelecidas nas normas, considerando que os postes, equipamentos e acessórios das redes de distribuição permanecem, em cada local, de acordo com os padrões de engenharia e que não existe nenhum fator externo de interferência.

Mas a situação na prática é bem diferente. Os postes, na realidade, se constituem em elementos que fazem parte da paisagem urbana e são utilizados paralelamente para outras finalidades, autorizadas ou não. O poste pode conter, além das redes elétricas, também cabos telefônicos e de televisão, condutores, luminárias e outros equipamentos de iluminação pública, placas de identificação das ruas e de sinalização do trânsito, cartazes e faixas de propagandas, condutores clandestinos, etc. É também muito comum encontrar o posicionamento das estruturas e equipamentos fora das especificações estabelecidas pelos padrões para montagem e construção de redes aéreas.

Todas estas situações acabam influenciando os procedimentos para a realização dos serviços, desde a dificuldade para o correto posicionamento da escada, por exemplo, até a locomoção do eletricista sobre o poste o que pode levá-lo, instintivamente, a adotar ações e posturas inadequadas.

Então, quando nos referimos ao local de trabalho, além do logradouro em si, estamos também considerando o ponto de reparo (poste ou instalação do cliente). Dessa forma, pode-se dizer que as condições do meio ambiente onde o serviço é executado englobam as condições do ponto de reparo e as condições próprias da região específica. 
Geralmente, quando ocorre um acidente, as análises condicionam a apuração das causas apenas aos procedimentos normativos existentes, sem se aprofundar na investigação de outros aspectos que podem ter contribuído para o acidente, entre eles, os relativos ao meio ambiente onde a tarefa é executada. Dessa forma, cria-se uma lacuna em relação aos aspectos da prevenção de acidentes no que tange aos fatores ambientais, fato que estimulou a realização do presente estudo.

\section{SISTEMA DE PROTEC̣̃̃O DE SEGURANC̣A}

Existem várias definições para acidente. A definição extraída do dicionário Aurélio apresenta o acidente como "acontecimento imprevisto, infeliz, casual ou não de que resulta ferimento, dano, etc."(FERREIRA, 2001, p.11)

Acidente de Trabalho é definido pela ABNT como "ocorrência imprevista e indesejável, instantânea ou não, relacionada com o exercício do trabalho que provoca lesão pessoal ou de que decorre risco próximo ou remoto dessa lesão."(NBR 14280, seção 2.1)

Para Torreira (1999, p.25) o acidente é "todo acontecimento casual, fortuito, imprevisto; acontecimento infeliz casual ou não, do qual resulta ferimento, dano, estrago, prejuízo, avaria, ruína, etc."

Souza (1999, p.6) conceitua acidente como sendo "um evento não desejado que resulta em dano à pessoa, dano à propriedade ou perda no processo, a partir do contato com uma determinada fonte de energia ou substância acima do limite do corpo humano ou da estrutura".

Seja qual for a definição adotada, o fato é que para a concretização do acidente de trabalho é necessária a caracterização da lesão, que é decorrente do contato entre o agente (fonte de energia) e o alvo (vítima).

O sistema de proteção tem por finalidade interpor-se entre o agente agressivo e o alvo, buscando evitar a exposição. Pode ser permanente ou instalado durante emergências. Também é utilizado em operações perigosas e insalubres.

Segundo Cardelas (1999), o sistema de proteção individual protege apenas um indivíduo. Há equipamentos de proteção individual (EPI) (óculos e máscaras) e materiais de proteção individual (MPI) (cremes e pastas). O sistema de proteção coletiva (EPC) protege mais de um indivíduo. Exemplos: abrigo coletivo, casamata e cortina de água. Em alguns casos, a denominação proteção coletiva é utilizada para sistemas que na realidade são de contenção. Exemplo: enclausuramento de máquina para redução de ruído.
Barbosa Filho (2001, p.118) comenta que inicialmente deve haver a busca da eliminação das fontes, em seguida a busca do isolamento no meio entre o homem e a fonte e, por último os equipamentos de proteção individual.

Os sistemas de proteção atuam dentro de determinados limites para os quais foram projetados, construídos e testados. São utilizados para proteger pontos vulneráveis do alvo. O desempenho é especificado para determinado agente ou conjunto de agentes com determinadas intensidades ou concentrações.

\section{OS ACIDENTES NO SETOR ELÉTRICO}

Não existe uma fonte específica de dados sobre acidentes do trabalho exclusivamente em serviços nas redes de distribuição de energia elétrica. Também são incluídos nas estatísticas os acidentes ocorridos em todas as atividades das empresas. Porém, como a distribuição agrega a maior quantidade de pessoas e é onde ocorre a maioria dos acidentes, acaba também exercendo a maior influência nas estatísticas do setor elétrico.

Os dados relativos aos acidentes com os eletricitários, categoria profissional que atua com os serviços em redes de alta, média e baixa tensão entre a geração, a transmissão e distribuição de energia elétrica, atualmente, são feitos pela Fundação COGE (Comitê de Gestão Empresarial), que assumiu a incumbência que era atribuída ao GRIDIS (Grupo de Intercâmbio e Difusão de Informações sobre Engenharia de Segurança e Medicina do Trabalho).

\section{sistema de proteção tem por finalidade interpor-se entre o agente agressivo e o alvo buscando evitar a exposição.}

Com a privatização das empresas concessionárias de energia, a partir de 1995, a terceirização dos serviços em rede de distribuição veio aumentando, gradativamente, representando hoje, na Light, por exemplo, algo em torno de $70 \%$ do efetivo operacional.

Como a estatística oficial das empresas engloba apenas os acidentes próprios, não considerando o serviço terceirizado, significa que os dados oficiais, atualmente, não permitem uma análise confiável. Optamos em apresentar os dados relativos aos anos de 1996 e 1997 por ser o período que marca a fase em que o processo de privatização estava em sua fase inicial e grande parte dos serviços operacionais ainda era efetuada com mão-de-obra própria.

Conforme o GRIDIS, em um universo de 52.452 eletricitários, pertencentes a 23 empresas, foram registrados 
2.043 acidentes de trabalho em 1997, sendo nove com morte (VIEGAS,1998)

É importante salientar, que nem todas as empresas informam todos os dados à entidade, sendo muito difícil a tentativa de estatísticas comparativas. O quadro 4 apresenta a estatística de acidentes de trabalho dos anos de 1996 e 1997, elaborada pelo GRIDIS, relativa às empresas cujos dados puderam ser comparados.

\section{Incidência de acidentes}

O Quadro 5 mostra os tipos de acidentes de maior incidência dentre as empresas do setor elétrico. Percebemos que os danos por exposição à energia elétrica, surpreendentemente, não configuram o tipo de acidente que apresenta a maior incidência, pelo menos entre os eletricitários. De acordo com o levantamento do GRIDIS, impactos sofridos pelos trabalhadores e queda com diferença de nível foram os acidentes mais comuns registrados entre a categoria.

\section{Atos inseguros e natureza das lesões}

Os Quadros 6 e 7 demonstram que os principais atos de insegurança, durante o trabalho em redes elétricas são descuidos, postura ou posição insegura, não uso de EPIs e uso indevido da parte do corpo.
É importante ressaltar que, praticamente, não existem dados relativos a acidentes com turmas terceirizadas.

\section{METODOLOGIA}

A metodologia utilizada para a realização do trabalho consistiu basicamente em pesquisa bibliográfica e pesquisa de campo. A pesquisa bibliográfica foi desenvolvida buscando-se associar os diversos elementos conceituais referentes à segurança do trabalho com as características dos serviços emergenciais em redes de distribuição de energia elétrica.

A escassez de obras específicas sobre o assunto nos proporcionou uma pesquisa, como diz Lakatos (1991), não apenas como uma mera repetição do que já foi dito ou escrito, mas como um exame do tema sob novo enfoque.

O tipo de pesquisa de campo realizada foi o que Lakatos (1991) define como pesquisa exploratória com utilização de procedimentos específicos para coleta de dados. O procedimento utilizado foi baseado numa técnica conhecida como "Técnica dos Incidentes Críticos", que consiste na identificação de incidentes e acidentes de pequena gravidade que não tenham sido relatados. Sua aplicação consiste em entrevistar um certo número de pessoas que tenham executado serviços específicos dentro de determinados

Quadro 4: Estatística de acidentes de trabalho com eletricitários.

\begin{tabular}{|c|c|c|c|c|}
\hline \multicolumn{5}{|c|}{ ESTATÍSTIGAS DE ACIDENTES DE TRABALHO COM ELETRICITÁRIOS } \\
\hline \multicolumn{5}{|c|}{ REDES dE ALTA E MÉdIA tENSÃo } \\
\hline \multirow[t]{2}{*}{ EMPRESA } & \multicolumn{2}{|c|}{ TOTAL GERAL } & \multicolumn{2}{|c|}{ FATAIS } \\
\hline & 1996 & 1997 & 1996 & 1997 \\
\hline Cia. Energética de Brasília & 37 & 30 & 0 & 0 \\
\hline Cia. Energética do Rio Grande do Norte & 23 & 37 & 0 & 0 \\
\hline Cia. Energética de Pernambuco & 186 & 237 & 1 & 1 \\
\hline Cia. Energética São Francisco & 131 & 138 & 2 & 1 \\
\hline Light & 345 & 183 & 6 & 0 \\
\hline Cia. Energética do Rio de Janeiro & 19 & 20 & 0 & 0 \\
\hline Cia Energética de São Paulo & 158 & 24 & 3 & 0 \\
\hline Cia. Paranaense de Energia & 148 & 138 & 3 & 3 \\
\hline Centrais Elétricas de Santa Catarina & 66 & 3 & 1 & 2 \\
\hline Cia. Elétrica de Minas Gerais & 602 & 331 & 4 & 0 \\
\hline Itaipu & 49 & 42 & 0 & 0 \\
\hline Furnas & 261 & 203 & 1 & 0 \\
\hline Eletrobrás & 50 & 33 & 0 & 0 \\
\hline Centro de Pesquisa em Energia Elétrica & 8 & 131 & 0 & 0 \\
\hline Cia. Estadual de Energia Elétrica & 327 & 169 & 3 & 1 \\
\hline
\end{tabular}

Fonte: GRIDIS (VIEGAS, 1998). 
ambientes, pedindo para que descrevam atos inseguros que tenham cometido ou observado e condições inseguras que tenham chamado sua atenção. Os participantes são estimulados a descrever tantos "incidentes críticos" quanto eles possam recordar, sem se importar se resultaram ou não em lesão, ou dano à propriedade (CARDELA, 1999, p. 151; SOUZA, 1999, p. 85). Lakatos (1991) classifica essa forma de entrevista como sendo do tipo despadronizada e não dirigida, onde há liberdade total por parte do entrevistado, que poderá expressar suas opiniões e sentimentos. A função do entrevistador é de incentivo, levando o informante a falar sobre determinado assunto, sem, entretanto, forçá-lo a responder.

\section{IDENTIFICAC̣̃̃O DOS RISCOS E SISTEMA DE PROTEC̣ÃO}

Procuramos, através da análise dos procedimentos normativos existentes para as diversas tarefas desenvolvidas nos serviços emergenciais, identificar os riscos reconhecidamente presentes nessas atividades, sua influência

\section{Quadro 5: Tipos de Acidentes} em ordem decrescente de incidência.

TIPOS DE ACIDENTES DE MAIOR INCIDÊNCIA

\begin{tabular}{|c|}
\hline Impacto sofrido por pessoa \\
\hline Queda com diferença de nível \\
\hline Reação do corpo \\
\hline Queda no mesmo nível \\
\hline Ataque de ser vivo \\
\hline Atrito ou abrasão \\
\hline Exposição à energia elétrica \\
\hline Esforço excessivo \\
\hline Aprisionamento em, sob ou entre \\
\hline Outros \\
\hline
\end{tabular}

Fonte: GRIDIS (VIEGAS, 1998).

Quadro 6: Atos Inseguros de maior incidência em ordem decrescente.

\section{ATOS INSEGUROS DE MAIOR INCIDÊNCIA}

Descuidar-se

\begin{tabular}{|c|}
\hline Descuidar-se \\
\hline Assumir posição / postura insegura \\
\hline Deixar de usar EPI disponível \\
\hline Usar parte do corpo impropriamente \\
\hline Dirigir incorretamente \\
\hline Usar equipamento de maneira imprópria \\
\hline Outros \\
\hline
\end{tabular}

Fonte: GRIDIS (VIEGAS, 1998). para a ocorrência de acidentes e os níveis de controle e proteção. Percebemos que quase todos os serviços seguem a mesma linha, só se diferenciando basicamente na execução prática do reparo, ou seja, todos se referem à preparação do local, ao trabalho com escadas, à postura para o trabalho, aos cuidados com a eletricidade e à influência do meio ambiente. Então, para a realização do estudo escolhemos um procedimento normativo que pudesse espelhar as diversas situações características desses serviços. Os procedimentos normativos operacionais na Light são denominados Procedimento Técnico Light (PTL).

O escolhido foi o "Procedimento Técnico para Operação de Chaves sem Dispositivo de Abertura em Carga" (PTL 0241 DT/96). Essas chaves funcionam como interruptores que seccionam (chaves de faca) e/ ou protegem (chaves fusíveis) os circuitos de Alta Tensão. Todas as vezes que ocorrem interrupções nos referidos circuitos, são realizadas várias manobras de abertura e fechamento das chaves, com o intuito de identificar e isolar o local do defeito. O mesmo tipo de manobra também é utilizado para a transferência de carga entre circuitos, fato bastante comum em sistemas de distribuição e também realizado pelas equipes de emergência.

Procurando destacar os riscos apontados no procedimento técnico analisado, elaboramos um resumo, apresentado no Quadro 8, cuja primeira coluna mostra os riscos descritos, a segunda coluna associa os riscos relacionados com os prováveis tipos de acidentes pessoais conseqüentes, de acordo com a NBR 14280, seção 5.3.2 e a terceira coluna assinala a existência ou não de proteção para cada tipo de risco, apontada no PTL. Consideramos a existência de proteção apenas nos casos em que a mesma tenha efetivamente condições de evitar a lesão, interpondo-se entre o agente agressivo (fonte) e o alvo (homem).

A análise mostra que $70 \%$ dos riscos apontados no procedimento normativo da empresa para a execução do serviço não possuem um sistema de proteção eficiente, ficando o controle resumido a recomendações, avisos, alertas e sinalizações.

\section{Quadro 7: Localização das lesões}

\begin{tabular}{|c|c|}
\hline \multicolumn{2}{|c|}{ LOCALIZAÇÃO DAS LESÕES } \\
\hline Parte do Corpo & Percentual \\
\hline Membros inferiores & $38,13 \%$ \\
\hline Membros superiores & $29,68 \%$ \\
\hline Tronco & $13,22 \%$ \\
\hline Face & $8,94 \%$ \\
\hline Cabeça & $8,14 \%$ \\
\hline Outros & $1,8 \%$ \\
\hline
\end{tabular}

Fonte: GRIDIS (VIEGAS, 1998). 


\section{IDENTIFICACÃO DOS FATORES AMBIENTAIS}

Para a identificação dos fatores ambientais foi utilizada a técnica do incidente crítico, descrita anteriormente, que consiste na identificação de incidentes e acidentes de pequena gravidade que não tenham sido relatados, através de entrevistas com os trabalhadores.

Visando manter a uniformidade das informações obtidas, concentramos o estudo apenas nos funcionários da empresa, não considerando os terceirizados.

Para garantir a colaboração dos trabalhadores, a fidedignidade das informações e limitar as influências pessoais, alguns cuidados tiveram que ser tomados, tais como: nível de informalidade que deixasse os profissionais bem descontraídos; não utilização de registros ou gravações, bastando algumas poucas anotações; bastante clareza quanto ao teor e objetivos do trabalho.
Tivemos também a preocupação de procurar um ambiente propício que estimulasse a participação dos trabalhadores. A exemplo das chamadas "reuniões diárias de segurança", na Light existe um programa chamado "Bom Dia Trabalhador", que consiste em reuniões periódicas realizadas nos diversos setores, onde os trabalhadores se reúnem para discutir assuntos ligados à prevenção de acidentes. Os próprios trabalhadores são os responsáveis pela organização e coordenação das reuniões, onde os gerentes e supervisores são simples participantes e o espaço é aberto para considerações e reivindicações sobre os aspectos de segurança e condições de trabalho.

A maioria dos dados foi coletada durante essas reuniões, aproveitando o ambiente propício, onde os trabalhadores foram estimulados a narrar suas experiências como participantes e observadores de quaisquer tipos de incidentes ocorridos durante o trabalho.

Dentre os incidentes narrados, relacionamos aqueles que representassem cada situação, referente aos diferentes tipos

Quadro 8: Análise dos riscos apontados no procedimento técnico em relação aos tipos de acidentes pessoais relacionados e ao sistema de proteção existente.

\begin{tabular}{|c|c|c|}
\hline $\begin{array}{l}\text { RISCOS APONTADOS NO } \\
\text { PROCEDIMENTO TÉCNICO }\end{array}$ & $\begin{array}{l}\text { TIPOS DE ACIDENTES } \\
\text { PESSOAIS (NBR 14280) }\end{array}$ & $\begin{array}{l}\text { POSSUI SISTEMA } \\
\text { DE PROTEÇÃO }\end{array}$ \\
\hline 1 - Abalroamento & Impacto sofrido por pessoa & Não \\
\hline 2 - Colisão & Impacto sofrido por pessoa & Não \\
\hline 3 - Atropelamento & Impacto sofrido por pessoa & Não \\
\hline 4 - Ataque de insetos/ animais & Provenientes de Animais & Não \\
\hline 5 - Piso irregular & Queda no mesmo nível & Não \\
\hline 6 - Piso escorregadio & Queda no mesmo nível & Não \\
\hline 7 - Hostilidade & Agressão humana & Não \\
\hline 8 - Planejamento incorreto & Correlato a vários tipos & Não \\
\hline 9 - Acidentes com terceiros/ bens & Correlato a vários tipos & Não \\
\hline 10 - Queda do poste & Queda com diferença de nível & Não \\
\hline 11 - Quebra do poste & Queda com diferença de nível & Não \\
\hline 12 - Lesão nas mãos & Aprisionamento, atrito, abrasão, corte & Sim \\
\hline 13 - Lesão nos pés & Aprisionamento, atrito, abrasão, corte & Sim \\
\hline 14 - Lesão nos olhos & Corpo estranho no olho & Sim \\
\hline 15 - Lesão na cabeça & Impacto sofrido por objeto que cai & Sim \\
\hline 16 - Entorse muscular & Esforço excessivo & Não \\
\hline 17 - Torção lombar & Reação do corpo a seus movimentos & Não \\
\hline 18 - Impacto da escada & Impacto sofrido por pessoa & Não \\
\hline 19 - Equipamento inadequado & Correlato a vários tipos & Não \\
\hline 20 - Queda do eletricista durante a subida e descida & Queda com diferença de nível & Não \\
\hline 21 - Queda do eletricista durante a realização da tarefa & Queda com diferença de nível & Sim \\
\hline 22 - Informações incorretas & Correlato a vários tipos & Não \\
\hline 23 - Classe de tensão das luvas incompatível & Exposição à energia elétrica & Não \\
\hline 24 - Queda do bastão & Impacto sofrido por objeto que cai & Não \\
\hline 25 - Abertura de arco voltaico & Exposição à energia elétrica & Sim \\
\hline 26 - Choque elétrico & Exposição à energia elétrica & Sim \\
\hline
\end{tabular}


de influência ambiental. Os registros foram feitos procurando manter a forma da descrição e o tipo de linguagem dos trabalhadores, também contendo, no final de cada narração, um breve comentário dos mesmos sobre a influência dos fatores no dia-a-dia.

A partir dos incidentes descritos, identificamos os fatores ambientais influentes na segurança dos serviços operacionais em redes aéreas de distribuição. Em seguida, relacionamos os fatores identificados com as Condições Ambientais de Insegurança estabelecidas pela NBR 14280, conforme apresentado no Quadro 9.

A fim de confirmar os fatores identificados, entrevistamos cerca de 84 profissionais, eletricistas e técnicos, entre os 156 que atuam em serviços emergenciais na região estudada.

Os dados foram coletados através do preenchimento de formulários sugerindo que os entrevistados indicassem dentre os fatores ambientais identificados aqueles que já lhes criaram situações que poderiam ter resultado em acidentes. A Figura 2 apresenta o gráfico resumo dos resultado obtidos.

Quadro 9: Fatores Ambientais Influentes na Segurança dos Serviços Operacionais em Redes Aéreas de Distribuição de Energia elétrica.

\begin{tabular}{|c|l|l|}
\hline GASO & \multicolumn{1}{|c|}{ FATOR AMBIENTAL } & \multicolumn{1}{|c|}{$\begin{array}{c}\text { CONDIçÃO AMBIENTE DE INSEGURANÇA } \\
\text { (NBR 14280) }\end{array}$} \\
\hline 1 & Pouca iluminação & lluminação inadequada \\
\hline 2 & Chuva / tempestade/ ventania & Exposição aos fenômenos da natureza \\
\hline 3 & Irregularidade ou instabilidade do terreno & Riscos da natureza \\
\hline 4 & Dependências inseguras de terceiros & Riscos inerentes às dependências inseguras de terceiros \\
\hline 5 & Poste na beira de valas e rios. & Riscos da natureza/ mal projetado \\
\hline 6 & $\begin{array}{l}\text { Poste congestionado por estruturas e } \\
\text { outros objetos estranhos às redes elétricas }\end{array}$ & Problema de espaço e circulação/mal projetado \\
\hline 7 & Trânsito intenso & Riscos relacionados com o trânsito \\
\hline 8 & Açães agressivas da comunidade & Riscos relacionados com o ambiente público \\
\hline 9 & Presença e ações de animais & Presença de animais \\
\hline 10 & Sol quente/ forte calor & Exposição aos fenômenos da natureza \\
\hline 11 & Postes e estruturas fora do padrão & Mal projetado/mal construído \\
\hline
\end{tabular}

Figura 2: Incidência dos Fatores Ambientais Segundo a Experiência dos Trabalhadores.

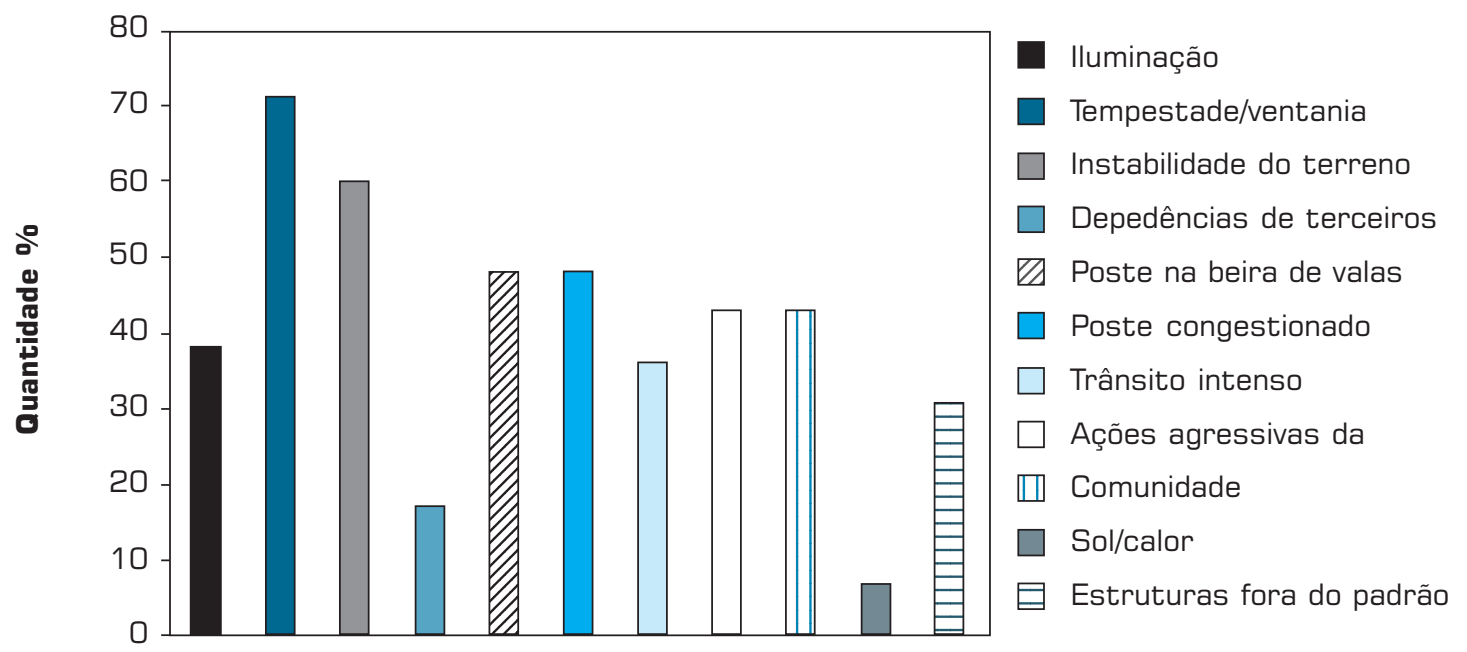

Fatores Ambientais 
O gráfico da Figura 2 mostra que todos os fatores identificados, anteriormente, já causaram situações que poderiam resultar em acidentes, confirmando a existência de riscos associados a esses fatores. $\mathrm{O}$ fator de maior incidência (tempestade/ ventania) já afetou a $71 \%$ dos entrevistados enquanto o de menor incidência (sol/ calor) já causou situações de perigo a $7 \%$. O fator relativo a irregularidades do terreno também apresentou considerável incidência, seguido das situações relativas ao posicionamento e congestionamento dos postes, e das ações de seres vivos (animais e pessoas), situação própria dos serviços no ambiente público.

\section{CONCLUSÕES}

A importância da energia elétrica na vida das pessoas fazse sentir a cada momento. Recentemente, no Brasil, a situação foi evidenciada em função da escassez da oferta de energia elétrica e da possibilidade de interrupção do fornecimento como forma de racionamento. O programa de racionamento, imposto pelo governo, mudou os hábitos de milhões de pessoas, empresas e instituições públicas. Trouxe à tona o receio dos chamados "apagões", que acabaram acontecendo, não pelo racionamento, mas devido a falhas no sistema de transmissão, fato que foi suficiente para transtornar as principais cidades do País e mostrar a significância da energia elétrica na civilização moderna.

É aí que também se faz sentir a importância dos reparos emergenciais nas redes de distribuição de energia elétrica, e o que influencia o estado de espírito das equipes de emergência. "Não há como relutar. O trabalho tem que ser feito, e a energia restabelecida, o mais rápido possível".

Vamos imaginar um eletricista à noite, sob forte temporal, tendo que realizar o reparo de um transformador para restabelecer a energia em um bairro de classe média. Garantir que o eletricista cumprirá todos os procedimentos técnicos e de segurança estabelecidos para as diversas etapas do reparo só mesmo se o homem fosse imune a sentimentos, estresses e outras influências comportamentais (MELO at al., 2001).

Conforme abordado durante o texto, a característica do trabalho nas ruas com exposição às manifestações da natureza e do ambiente público, associadas à imprevisibilidade e à rapidez exigida, faz sobressair o nível de risco dos serviços emergenciais.

As formas de controle para as ações preventivas têm origem nas investigações e análises de acidentes, que por sua vez são limitadas às causas imediatas, visíveis, normalmente tendendo para o ato inseguro, justificado pelo não cumprimento das instruções contidas nos procedimentos normativos.

Em relação aos procedimentos normativos, Llory (1999), comenta que a concepção administrativa do trabalho, predominante entre os responsáveis, empresários e consultores especialistas em organização, pressupõe que a normatização resolve todos os problemas e todas as dificuldades do trabalho. Entretanto, não é assim que ocorre na realidade. Não é possível durante a elaboração de um procedimento levar em conta todas as combinações complexas de eventualidades, de acontecimentos e dos possíveis cenários. O que está escrito é apenas a representação de um trabalho imóvel, frio, abstrato, enrijecido numa certa quantidade de instruções técnicas.

O trabalho real pressupõe a interação do homem no meio ambiente, numa relação influenciada pelos sentimentos e sensibilidades próprias dos seres humanos e as manifestações desses ambientes.

Dessa maneira, retomando as questões centrais do problema, buscou-se, com uma visão mais ampla no aspecto dos acidentes e da prevenção nos serviços emergenciais em redes aéreas de distribuição de energia elétrica, identificar os fatores ambientais capazes de influenciar as condições de segurança a partir da análise das relações entre os procedimentos normativos e o trabalho real desenvolvido pelas equipes.

O procedimento técnico analisado mostrou que a segurança nos serviços depende mais de ações preventivas do próprio trabalhador do que, propriamente, das ações de controle da empresa e dos meios de proteção existentes. O Quadro 8 mostra que a maioria dos riscos apontados na PTL não possui proteção capaz de se interpor entre o homem e a fonte, significando, então, que a empresa, através de seu instrumento normativo, admite que os trabalhadores nestas atividades estão sujeitos a uma série de acidentes provenientes de fatores não controlados. Assim, se a realidade da emergência é a execução imediata, e existem riscos nos locais de trabalho sem sistema de proteção adequado, pode-se dizer que as equipes trabalham, normalmente, expostas a determinados riscos não controlados, confirmando uma das questões estabelecidas para estudo, ou seja, os serviços emergenciais, em redes aéreas de distribuição são realizados permanentemente em condições ambientais de insegurança.

$\mathrm{O}$ registro e as descrições dos incidentes vivenciados pelos profissionais mostrou de uma maneira prática, a influência dos fatores ambientais na ocorrência de acidentes, confirmando que os riscos provenientes do meio ambiente podem comprometer os procedimentos de prevenção existentes e contribuir direta e indiretamente para a ocorrência de acidentes durante os serviços emergenciais em redes aéreas de distribuição de energia elétrica.

A identificação dos fatores ambientais e a experiência dos profissionais, apresentadas na Figura 2, se constituem em elementos preciosos para a melhoria dos métodos de prevenção nos serviços emergenciais em redes aéreas de distribuição. Pode-se destacar a apreensão dos trabalhadores em relação aos acidentes provenientes de ataques de 
seres vivos. Antes, se era praticamente relativa aos animais, passou a incorporar um forte componente que é a agressão humana, o que representa claramente o reflexo da violência urbana.

A prevenção da maioria dos riscos provenientes dos fatores ambientais independe de ações prévias da empresa, e eles se agravam devido às características emergenciais dos serviços. Dessa forma, a identificação dos riscos e as ações preventivas deverão ser efetuadas pelos próprios eletricistas no momento da realização da tarefa, mostrando que o fator pessoal é o elemento mais importante para a prevenção de acidentes nos serviços emergenciais em redes aéreas de distribuição.

A própria análise do PTL confirma a importância dos eletricistas para a confiabilidade da operação. Se as situações, nessas atividades, são marcadas por imprevistos e incertezas, são eles que tomam as decisões finais sobre a posição diante das adversidades.
Devido talvez à superficialidade dos procedimentos prescritos e à imprevisibilidade das situações, os eletricistas são levados a elaborar modos operatórios originais, muitas vezes contraditórios às normas prescritas. Assim, torna-se importante para a segurança a capacidade das iniciativas individuais ante o inesperado, o que implica a presença de conhecimento, habilidade e troca de experiência entre os trabalhadores.

As empresas responsáveis pela execução dos serviços emergenciais em redes de distribuição de energia elétrica devem admitir que a realidade do serviço contém particularidades que o diferem das outras atividades industriais, e até mesmo das outras atividades em redes de distribuição. Qualquer sistema de prevenção que busque, efetivamente, a redução dos acidentes nessas empresas deve partir do reconhecimento da realidade das condições ambientais de insegurança, para então procurar combater as variáveis dos fatores ambientais de maior contribuição para o acidente.

\section{Edição especial início 07/03/2003 fim $25 / 08 / 2003$}

\section{- Bibliografia}

AGÊNCIA NACIONAL DE ENERGIA ELÉTRICA. RESOLUÇÃO 456: Condições Gerais de Fornecimento de Energia Elétrica. Brasília, 2000.

ASSOCIAÇÃO BRASILEIRA DE NORMAS TÉCNICAS. NBR 14280: Cadastro de acidentes do trabalho - Procedimento e classificação. Rio de Janeiro, 1999.

BALLENTINE, R.; MURPHY, C. The Winds of Change. Transmission \& Distribution, Overland Park, v. 53, n. 2, p. 34-43, fev. 2001.

BARBOSA FILHO, A. N. Segurança do Trabalho \& Gestão Ambiental. São Paulo : Atlas, 2001.

BOM DIA TRABALHADOR, Atas de Reunião. Rio de Janeiro: Light, 2001.

BRASIL. Norma Regulamentadora -NR 9. Programa de Prevenção de Riscos Ambientais. In: Manuais de Legislação Atlas. 35. São Paulo: Atlas, 1997. 16 v.

BRITISH STANDARDS INSTITUTION. BS 8800: Guia para Sistema de Gestão de Saúde e Segurança Ocupacional. Londres, 1996.
CARDELA, B. Segurança no Trabalho e Prevenção de Acidentes. São Paulo: Atlas, 1999.

COMITÊ DE DISTRIBUIÇÃO. Relatório CODI-2.2.16.13.1: Gestão de Manutenção da Distribuição - Tema 16 - Manutenção da rede de Distribuição. Rio de Janeiro, 1995.

CREDER, H. Instalações Elétricas. Rio de Janeiro: Campus, 1986

ELETROBRÁS. Planejamento de Sistemas de Distribuição. Rio de Janeiro: Campus, 1982.

FERREIRA, M. B.; ANJOS, M. (Ed.). Aurélio Século XXI: o dicionário da língua portuguesa. 4. ed. Rio de Janeiro: Nova Fronteira, 2000.

INFORMALIDADE à margem. Jornal do Brasil, Rio de Janeiro, 25 mar. 2001. Economia, p.3.

LAKATOS. Fundamentos de metodologia científica. São Paulo: Atlas, 1991.

LIGHT. PTL 0241DT/96: Operação de chaves sem dispositivo de abertura em carga - Procedimento Técnico de Acionamento - Distribuição. Rio de Janeiro, 1996.
LIMA, G. B. A. Sistema de Gestão-BS8800: anotações de aula. Mestrado Profissional em Sistemas de Gestão. Niterói: UFF, 2000.

LLORY, M. Acidentes Industriais. Rio de Janeiro: MultiMais Editorial, 1999.

MACHADO,J.M.H.; PORTO,M.F.S.; FREITAS, C. M. Perspectivas para uma análise interdisciplinar e participativa de acidentes no contexto da indústria de processo. In: Acidentes Industriais Ampliados. Rio de Janeiro: Fiocruz Editora, 2000. p. 49-81.

MELO, L. A., et al. A cultura de segurança como resultado de um processo de liderança eficaz. In: Encontro Nacional de Engenharia de Produção, 21, 2001, Salvador, Anais....

MELO, L. A. A Influência dos Fatores Ambientais na Segurança dos Serviços em Redes Aéreas de Distribuição de Energia Elétrica: O Caso dos Serviços Emergenciais. 2002, 128f. Dissertação (Mestrado Profissional em Sistemas de Gestão) Centro Técnológico da Universidade Federal Fluminense, Niterói. 2002.
MORAES, A. L. O.; CUNHA, C. R. F. Análise de Segurança dos Serviços de Construção e Manutenção de Redes Aéreas de Distribuição de Energia Elétrica, 2001.114 f. Trabalho de Conclusão de Curso (PósGraduação em Engenharia de Segurança) - Universidade Federal Fluminense, Niterói. 2001.

MUSSER, P. The Emergence of the Outsourced Utility. Transmission 8 Distribution, Overland Park, v. 53, n.1, p. 50-57, Jan. 2001.

SENIA, A. The California Meltdown Transmission \& Distribution, Overland Park, v. 53, n.3, p.20-28, Mar. 2001.

SOUZA, C. R. C. Análise e Gerenciamento de Riscos de Processos Industriais. Apostila (Pós-Graduação em Engenharia de Segurança) - Universidade Federal Fluminense, Niterói. 1999.

TORREIRA, R. P. Manual de Segurança Industrial. São Paulo: Margus, 1999.

VIEGAS, C. Trabalho com eletricidade: Quadro sério. In: CD-ROM Revista Proteção 10 anos. Novo Hamburgo, ed. 77-98, 1998. 